\title{
INVESTIGACIONES
}

\section{Migración latinoamericana en situación de marginalidad. Campamentos y educación en Antofagasta, 2012-2018*}

\author{
Latin American migration in a marginality situation. \\ Camps and education in Antofagasta, 2012-2018
}

\author{
José Antonio González Pizarro ${ }^{a}$, Paulina Montserrat González Tello \\ ${ }^{a}$ Centro de Estudios Histórico-Jurídicos de la Facultad de Ciencias Jurídicas. Universidad Católica del Norte. \\ jagonzal@ucn.cl \\ ${ }^{b}$ Dirección de Pastoral Universitaria y Cultura Cristiana. Universidad Católica del Norte. \\ pgonzalez02@ucn.cl
} \begin{abstract}
capital, Antofagasta, desde el año 2012.
En tal sentido, el artículo se centra en cuatro ejes que han significado la visibilidad migratoria con repercusiones a nivel nacional:

1. Las características de los componentes humanos, en cuanto al género, procedencia geográfica, nivel instruccional y su inserción en la sociedad regional.

2. La relación de respeto a los derechos humanos exigidos por el derecho internacional y la adecuación de la normativa nacional en materias de derechos del migrante.

3. Su asentamiento en la ciudad de Antofagasta, principalmente en campamentos, constituyendo una realidad habitacional diferencial a las poblaciones populares.

4. Las dimensiones del resguardo del niño/joven migrante en materias educacionales y las prácticas de modelos interculturales en los niveles básico, medio.
\end{abstract}

El trabajo aborda la complejidad del proceso inmigratorio que vive la región de Antofagasta y, especialmente, su

Palabras claves: Migración latinoamericana, derechos, educación, Antofagasta.

\section{ABSTRACT}

This paper addresses the complexity of the immigration process experienced by Antofagasta Region, particularly, its capital city, Antofagasta, since 2012.

In this sense, the paper focuses on four axes leading to migration visibility with effects on a national basis:

1. The characteristics of human components concerning gender, geographic origin, instructional level, and their insertion in the regional society.

2. The relationship with human rights demanded by international law and the adaptation of national regulations concerning migrants' rights.

3. Their settlement in Antofagasta city, mainly in camps, thus leading to a housing reality different than low-class neighborhoods.

4. The dimensions for safeguarding migrant children/youth in educational matters and the use of intercultural models in primary and secondary school.

Key words: Migration, Latin American, rights, education, Antofagasta.

* El artículo forma parte del Proyecto IMI-UCN de la Vicerrectoría de Investigación y Desarrollo Tecnológico de la Universidad Católica del Norte- Minera La Escondida. 


\section{INTRODUCCIÓN}

La región de Antofagasta ha sido una tierra de migraciones. La ciudad de Antofagasta fundada en 1868, durante la administración boliviana, constituyó un ejemplo de la contribución migratoria chilena y europea, en su construcción social general. Sus instituciones, sus actividades comerciales, financieras y sociales pudieron erigirse al esfuerzo de esta migración. Tales flujos fueron acompañados por la bonanza que trajo la industria salitrera, que sostuvo la viabilidad de la urbe y su hinterland por más de medio siglo, coincidiendo con la primera globalización influenciada por el liberalismo económico y político que incidió en las políticas nacionales, en el lapso de 1875 a 1920 (González, 2014).

Si el censo de 1907 indicó la mayor presencia extranjera en la región y en el país, el censo de 2017 (modificando el fallido de 2012), ha recogido que la proporción de extranjeros con la población nacional, ha excedido el 4\% de 1907 igualándose el porcentaje en el 2017, constatándose en la ciudad de Antofagasta un explosivo incremento de la inmigración que se ha traducido en oportunidades y problemas. Entre los primeros, poner en acción las prácticas sociales en pro de una sociedad democrática, más plural, incluyente y tolerante, ante una presencia demográfica no acostumbrada a ser percibida en las arterias urbanas, en los locales comerciales, en el vecindario popular, como es la migración colombiana, que ha significado confrontar actitudes subjetivas y colectivas ante el racismo, la xenofobia. En los segundos, ha significado tensionar el aparato público y edilicio respecto a la cobertura de los servicios básicos, de salud, educación y vivienda, como también paliar la orientación de la legislación migratoria de 1975 no proclive a considerar al migrante como un sujeto de derechos. En tal perspectiva, se ha tenido que apreciar un pendular de la opinión pública regional sobre la mirada al migrante que no ha estado lejos de preocupar por los signos de rechazo que encubren posturas de racismo, clasismo, xenofobia y paralelamente ver la actuación de organizaciones civiles -como las universidades, puntuales ONG- en pro de modificar tal estado de situación, moviendo a determinadas agencias estatales y municipales a implementar políticas y acciones de mayor inserción del migrante en la sociedad local de Antofagasta.

Nos interesa contextualizar la situación del inmigrante de cara ante las agencias estatales y edilicias, desde su condición de marginalidad dual, espacial (viviendo en campamentos) y social (proceso de regularización de su estada e inserción en la sociedad) y cómo en este marco logra impactar al estado y la sociedad para alterar las políticas públicas ante lo inédito del acelerado proceso migratorio en Antofagasta. ¿Cómo logra superar las vallas que encuentra desde su llegada al país? ¿De qué manera se implementan las acciones estatales y de las organizaciones civiles en pro de la inclusión social del inmigrante? ¿Cómo explicarse las reacciones de la sociedad antofagastina respecto al inmigrante?

Todos estos elementos e interrogantes, justiprecian, a nuestro entender, el esfuerzo del inmigrante en su motivación personal, considerando su cualificación laboral sobre la media nacional, que lo hace sobreponerse a sus frustraciones que le produce el ambiente urbano, por un lado, y las diferentes acciones tendientes a plantear en el escenario educacional, los principios de una sociedad que aspira a verse como plural, tolerante, respetuosa ante la diversidad y plantear políticas pertinentes hacia tales objetivos/principios.

Nuestra visión combina los diversos estudios realizados en la comuna de Antofagasta con los resultados vistos desde el año 2010 (cuando la Universidad Católica del Norte realizó el primer seminario regional de migración) y un trabajo de campo en los últimos 
tres años en el denominado macro-campamento El Arenal, amén de una serie de entrevistas con autoridades del gobierno regional entre los años 2017-2018.

\section{LA EXPERIENCIA MIGRATORIA LATINOAMERICANA EN ANTOFAGASTA. UNA COMPARACIÓN}

Antofagasta tuvo en la era del salitre (1880-1920) una importante presencia latinoamericana, principalmente de las naciones vecinas, Bolivia, Perú y Argentina, siendo la primera que totalizaba el $40 \%$ de los extranjeros en la región y en Antofagasta. Tanto argentinos como bolivianos pudieron distribuirse en razón de su capital social tanto en las áreas rurales -que eran entonces consideradas erróneamente las oficinas salitreras, que superaban las 2.000 almas como población- y en las ciudades costeras. Tal situación de la cualificación laboral determinó su inserción espacial en la ciudad de Antofagasta, en áreas residenciales coincidentes con otros inmigrantes (González, 2011; González, Lufin y Galeno, 2014). Si se compara con la migración latinoamericana, de colombianos(as) y ecuatorianos(as), en el mismo periodo, se puede señalar que, siendo minoritaria en el marco de las colonias extranjeras, hacia 1920 alcanzan respectivamente, los colombianos el 15,7\% del total en Chile, y los ecuatorianos el 14,2\% del total de connacionales en el país.

La actividad de los colombianos como comerciantes, empleados y mecánicos arroja el $71 \%$ de empleabilidad, mientras para el caso de los ecuatorianos, los empleados, comerciantes y mecánicos alcanzan el $46 \%$ de representatividad (González, Lufin y Galeno, 2018).

Puede indicarse que el ambiente del liberalismo existente, hizo posible la movilidad transfronteriza sin mayores controles -salvo cuando en 1906 se firma el convenio policial de Buenos Aires para fiscalizar los elementos del anarquismo italiano y que incidió en la formación en nuestro país de los Prontuarios de Extranjería- que se correlacionó con la libertad de ejercicio de oficios variados como establecer almacenes de abarrotes en los sectores residenciales populares y optar si los niños pudiesen colaborar con el incremento de las remuneraciones familiares, pues en 1920 se estableció la ley de instrucción primaria obligatoria. En el caso de Antofagasta, los pocos establecimientos educacionales podían cubrir las necesidades de los sectores mesocráticos -con los liceos, escuela de minas y los colegios confesionales- pero bajo la hegemonía de parámetros estatales de inclusión nacional, e incluso de los discentes de naciones fronterizas (González, 2017).

Sin embargo, un rasgo que caracterizó a la ciudad de Antofagasta durante el auge migratorio de 1907 fue, además del 19\% de su población regional era extranjera, fue el carácter cosmopolita y el aire globalizante-aunque fuese periférico por la influencia del salitre en los mercados internacionales- que posibilitó que, en la carencia de un plano regulador, la ocupación del espacio urbano posibilitara la convergencia de distintas nacionalidades, aunque la diferencia estribó en tres instancias: 1. Los patrones de nupcialidad de corte endogámico entre los europeos y más abierto -exogámicos- entre los latinoamericanos; 2. La protección social civil, mediante sociedad de socorros mutuos y/o beneficencia, establecida por los bolivianos y los europeos latinos, excepto los británicos y alemanes, los más influyentes y de mayor capital social y financiero y 3. Los circuitos cerrados de educación étnica para británicos y alemanes, posteriormente yugoslavos, a diferencia del elementos latinoamericano que acudió a los establecimientos fiscales (González, 2016). 
Las oleadas de flujos migratorios que ha debido sentir la ciudad de Antofagasta en la década de 2010, refieren a una situación que los analistas se han referido con meridiana claridad: el push and pull, que se ha traducido en las razones de la migración desde Colombia, Ecuador y ahora desde Venezuela, por la situación crítica tanto para las personas y familias de preservar su calidad de vida -si son profesionales o de oficios técnicoscomo del ambiente de seguridad personal, derivado de la violencia institucionalizada del narcotráfico, los paramilitares o la crisis económica aguda o bien institucional que golpea aún más la incertidumbre de un mundo globalizado amenazante a la periferia mundial. En contraste, un país que proyecta una imagen de crecimiento económico cierto pero que brinda estabilidad política e institucional a los proyectos a emprender y certeza a futuro, con amplias facilidades para ingresar bajo diversas modalidades que varían en los designios de sus beneficiados.

Si bien se ha hecho notar que las inmigraciones colombianas y ecuatorianas tuvieron un alza en la década de 1960 (Taylor, 2014; Martínez, s. f;) en Chile -un país que nunca se caracterizó como nación receptora de inmigración sino por el contrario- ha sido en los últimos años y con el país, la región y ciudad de Antofagasta, como centro receptor relevante del proceso inmigratorio latinoamericano.

Si se observa la estadística oficial entre los años 2005 a 2017, tenemos que la inflexión de esta inmigración se constata en el bienio 2010-2011, como se aprecia en la Tabla 1 (Departamento de Extranjería, 2018).

Tabla 1. Solicitudes de Residencia presentadas ante el Departamento de Extranjería y Migración de Antofagasta. Selección ${ }^{1}$

\begin{tabular}{|l|c|c|c|c|c|c|c|c|c|}
\hline Nación & $\mathbf{2 0 0 5}$ & $\mathbf{2 0 1 0}$ & $\mathbf{2 0 1 1}$ & $\mathbf{2 0 1 2}$ & $\mathbf{2 0 1 3}$ & $\mathbf{2 0 1 4}$ & $\mathbf{2 0 1 5}$ & $\mathbf{2 0 1 6}$ & $\mathbf{2 0 1 7}$ \\
\hline Argentina & 316 & 150 & 99 & 94 & 66 & 164 & 128 & 120 & 153 \\
\hline Bolivia & 361 & 729 & 853 & 1622 & 2378 & 4632 & 4146 & 3516 & 3602 \\
\hline Colombia & 218 & 1492 & 3113 & 4292 & 3975 & 7344 & 6611 & 6381 & 5667 \\
\hline Ecuador & 196 & 188 & 215 & 209 & 141 & 269 & 290 & 387 & 356 \\
\hline Perú & 1808 & 2244 & 1926 & 1987 & 1259 & 2178 & 1988 & 1509 & 1461 \\
\hline Venezuela & 4 & 7 & 11 & 15 & 27 & 45 & 82 & 263 & 660 \\
\hline
\end{tabular}

Fuente. Elaboración propia.

Para el tercer trimestre del año 2018, se puede apreciar el impacto del arribo de inmigrantes latinoamericanos no tradicionales, colombianos y venezolanos. Los colombianos llegados fueron 5274 representando el 37,91 \%; bolivianos con 4136 representan el $29,73 \%$, venezolanos con la cifra de 2144 constituyen el 15,41\%, los peruanos

En su nota metodológica, Departamento de Extranjería y Migración refiere que los datos corresponden a solicitudes de residencia presentadas en este servicio y no a extranjeros residentes en la provincia de Antofagasta. Sin embargo, en la interpretación cualitativa de los datos se pueden inferir tendencias respecto de la caracterización de los migrantes que residen en la provincia de Antofagasta. 
con 1420 contribuyen con el 10,21\% y los ecuatorianos con 331 con el 2,38\% cierra el aporte más relevante de los segmentos demográficos (Departamento de Extranjería, 2018).

Una diferencia con la anterior migración relevante en Antofagasta es la mayor proporción de mujeres en la actualidad y la coincidencia con grupos etarios juveniles y la mayor proporción de solteros que casados. Para el caso de las mujeres latinoamericanas en la era salitrera se puede analizar González, Lufin y Galeno (2017).

En el caso de la inmigración latinoamericana y, en general, de la inmigración extranjera en Antofagasta en el siglo XXI ésta se ha caracterizado por la feminización, como puede cotejarse en la siguiente Tabla 2.

Tabla 2. Inmigración general en la región de Antofagasta: género y estado civil

\begin{tabular}{|l|c|c|c|c|}
\hline Años & Femenino & Masculino & Casados & Solteros \\
\hline $\mathbf{2 0 0 5}$ & 1746 & 1502 & 650 & 2575 \\
\hline $\mathbf{2 0 0 6}$ & 1047 & 926 & 385 & 1582 \\
\hline $\mathbf{2 0 0 7}$ & 1180 & 1102 & 469 & 1799 \\
\hline $\mathbf{2 0 0 8}$ & 1315 & 1214 & 534 & 1976 \\
\hline $\mathbf{2 0 0 9}$ & 1869 & 1739 & 625 & 2943 \\
\hline $\mathbf{2 0 1 0}$ & 2688 & 2648 & 927 & 4342 \\
\hline $\mathbf{2 0 1 1}$ & 3374 & 3288 & 1043 & 5520 \\
\hline $\mathbf{2 0 1 2}$ & 4552 & 4149 & 1320 & 7264 \\
\hline $\mathbf{2 0 1 3}$ & 4153 & 4103 & 1109 & 3769 \\
\hline $\mathbf{2 0 1 4}$ & 7902 & 7396 & 1795 & 13290 \\
\hline $\mathbf{2 0 1 5}$ & 7094 & 6843 & 1094 & 12733 \\
\hline $\mathbf{2 0 1 6}$ & 6555 & 6428 & 736 & 12137 \\
\hline $\mathbf{2 0 1 7}$ & 6510 & 6290 & 632 & 11976 \\
\hline
\end{tabular}

Fuente. Departamento de Extranjería, 2017.

Esto ha significado que la mayor cantidad de inmigrantes latinoamericanos indicados haya decidido buscar su asentamiento en la ciudad de Antofagasta, planteándose, como veremos, la temática de las viviendas en los límites del espacio urbano a partir del año 2012.

Empero, el migrante latinoamericano ha podido sortear determinadas vallas, con relación a su capital tanto social como financiero, y abordar su inserción en el mercado laboral.

Investigaciones recientes (Seremi Salud, 2017; Fundación Casa de la Paz, 2018) han hecho notar la triada: preparación instruccional, trabajo e inclusión, señalando una distribución en el mercado laboral para el hombre inmigrante: empleado $(61,4 \%)$, estudiante $(14,5 \%)$ y empleado doméstico $(8,2 \%)$; la mujer inmigrante, principalmente como empleada, empleada doméstica y estudiante. En este sentido, el colectivo de los inmigrantes latinoamericanos no opera de modo uniforme. Los mejores preparados en términos 
profesionales o de cualificación laboral han visto superar su ingreso al promedio de los chilenos, estimándose por la CASEN 2015 en un 28\%, empero, no es lo mismo para todos (Casa de la Paz, 2018, pp. 15-16). La precariedad social del inmigrante se ve agravada por factores como el alto costo de la vida y un rasgo que caracteriza a los inmigrantes latinoamericanos en naciones con mejor desarrollo económico que sus países originarios: las remesas de dinero (Obach, Cabieses, Chepo y McIntyre, 2017).

Uno de los desafíos que han debido encarar los servicios básicos del Estado, como ser el ámbito de la salud, ha sido la constatación de patologías que se habían extinguido cuando no estaban bajo control o sensiblemente disminuido. En esta dirección, se ha hecho notar por la Seremi de Salud (Seremi Salud, 2017), el siguiente cuadro actualizado que ha provocado cierta alarma por las patologías por las que han sido atendidos los inmigrantes a nivel regional, siendo las poblaciones Bolivia, Colombia y Perú, las que totalizan el 64\% del total de notificaciones: Chagas, el 34,8\%, 258 casos; sífilis, 18,6\% con 138 casos, VIH con el 17,7\% con 131 casos, TBC con 12,8\% con 95 casos, Gonorrea con el 8,8\% con 65 casos. Si la enfermedad de Chagas afecta predominantemente a los inmigrantes de Bolivia, la Sífilis corresponde a la población femenina colombiana y el VIH a la población masculina colombiana. En contraste con los casos chilenos, Chagas un 12,8\% con 580 casos, Sífilis con $26,4 \%$ con 1.193 casos, VIH, con $15,8 \%$ con 714 casos, TBC con $8 \%$ con 362 casos y Gonorrea con 13,7\% con 621 casos.

Cabe indicar que esta clase de información fidedigna ha podido ser asumida por la población para acentuar su rechazo al inmigrante o bien para demandar mayor presupuesto en el área pertinente para atender su cobertura.

Aun con las dificultades que han tenido determinados segmentos inmigrantes en su inserción, los datos demuestran la decisión por establecerse definitivamente en el país y en la ciudad, como lo demuestra la Tabla 3 (Ministerio del Interior, 2014, p. 41).

Tabla 3. Solicitudes de concesión de permanencia definitiva

\begin{tabular}{|c|c|c|c|c|c|c|c|c|c|}
\hline $\mathbf{2 0 0 5}$ & $\mathbf{2 0 0 6}$ & $\mathbf{2 0 0 7}$ & $\mathbf{2 0 0 8}$ & $\mathbf{2 0 0 9}$ & $\mathbf{2 0 1 0}$ & $\mathbf{2 0 1 1}$ & $\mathbf{2 0 1 2}$ & $\mathbf{2 0 1 3}$ & $\mathbf{2 0 1 4}$ \\
\hline 498 & 632 & 762 & 950 & 3.634 & 1.194 & 1.747 & 3.413 & 3.463 & 6.219 \\
\hline
\end{tabular}

Fuente. Ministerio del Interior, 2014.

\section{UNA MIRADA A LA OBSERVANCIA DE LOS DERECHOS HUMANOS DE LOS MIGRANTES EN ANTOFAGASTA}

La llegada del inmigrante al país y a la ciudad de Antofagasta, plantea una serie de interrogantes sobre su estado de regularización o irregularidad en el país y este antecedente en gran medida marca las consecuencias de su estada en la nación. No obstante, si esto es lo empírico, lo fáctico-administrativo, existe otra dimensión más intangible, sinuosa, como es el manejo de las denominadas por Alfred Schultz como "pautas socio-culturales" como acuciantes para el extranjero para comprender los códigos de la sociedad local, y trabajar su estrategia de inserción. Sin embargo, detrás de tales pautas se ha podido explicar cómo se ha "naturalizado" determinadas prácticas y expresiones sociales, que esconden el racismo, 
la xenofobia y el clasismo de nuestra sociedad. Estas responden a un set de elementos que gatillan la respuesta ante el inmigrante, como ser la clase social, el sector donde vive, las redes sociales de contacto y la propia nacionalidad y etnia.

Si nos acercamos a la realidad del migrante como sujeto de derechos, podemos constatar la dificultad que se ha debido asumir. Para algunos, uno de los problemas que afecta a los inmigrantes es que dentro de la cobertura social estatal -aun disminuida- no ha sido considerado el colectivo de la población migrante: "Como un grupo vulnerable en el cual se deba focalizar la política pública social” (De las Heras, 2016, p. 6).

Un acercamiento a la relación del inmigrante con las entidades fiscales, esta plantea un problema que se bifurca. Una, de la carencia de las agencias estatales de los servicios administrativos para operar en tal observancia (desde un presupuesto limitado hasta falta de personal y más grave que, ante un "silencio" u "omisión" de atender al inmigrante se opte por la discrecionalidad administrativa) y otra de la capacidad de abordar en determinados ámbitos (salud, educación, etc.) la observación a las garantías de que está rodeado por el derecho internacional el sujeto migrante. Esto sin considerar, la capacidad de reacción estatal, tanto a nivel central, regional como edilicia, a establecer las condiciones de atención del inmigrante en tales niveles de la vida pública.

Empero, se ha podido realizar una lectura no tan unívoca sobre la accesibilidad de los inmigrantes a los servicios básicos. Un estudio refiere:

Una de las expresiones más patentes de este hecho está en las dificultades de acceso a servicios y beneficios estatales por parte de la población avecindada. Una de las cuestiones que más incide en la generación de hostilidad entre nacionales y extranjeros es precisamente el acceso diferencial y restringido a servicios y beneficios sociales por parte de unos y otros, lo que se agudiza cuando se desciende en los estratos socioeconómicos (Fundación Superación, 2017, p. 16).

Fue en la ciudad de Antofagasta, en el año 2014, cuando se generó una reacción frente a una injusticia sobre los hijos de inmigrantes en situación irregular. El abogado Ignacio Barrientos, nos refiere:

Esto fue el 2014, cuando recién empezamos a funcionar como migra-acción, enviamos una solicitud a registro civil, a la gobernación provincial a la intendencia, no recibimos respuestas, en ese momento teníamos alrededor de 5 casos, en algún momento se acercó un periodista a preguntar si teníamos alguna situación que podíamos plantear relacionada con el tema migratorio, y ahí surge esta situación, nosotros habíamos presentado el caso de una pareja de migrantes que ingresaron en forma ilegal tuvieron un hijo aquí en chile y el registro civil lo inscribió como hijo de extranjero transeúntes cosa que no nos pareció ya que está trasladando la situación de migrantes a su hijo, cosa que no corresponde, porque el carácter de extranjero transeúntes no está pensado en términos de cuál es la situación migratoria, una persona puede ser residente en Chile aun cuando tenga una situación migratoria irregular y presentamos el reclamo ante la corte suprema y fue aceptado (Entrevista Barrientos, 2018).

En este marco, hay una serie de regulaciones internacionales que constituyen el marco de acción para la normativa nacional, imponiéndose -por ser parte de lo macro 
de los derechos humanos, tanto en su parte general como específica- a la supremacía constitucional. Entre los ejes fundamentales pueden mencionarse los que atienden a los principios de no discriminación y el amplio espectro de normas que refieren derechos a los migrantes, su familia, los niños y niñas en los ámbitos de la educación, del trabajo. En tal sentido, las Naciones Unidas aprobó la "Convención Internacional para la Protección de los derechos de todos los trabajadores y sus familias", de 8 de junio del 2005; instrumento primordial para abordar la temática migratoria, reconociendo derechos civiles, políticos, sociales, económicos y culturales. Este conjunto de disposiciones se ha reconocido, apuntaba a formar un "marco para la gobernabilidad migratoria" (Stefoni, Acosta, Gaymer y Casas Cordero, 2010, pp. 22-23; Red Chilena de Migración, 2011). De modo sucinto, se puede indicar que la legislación migratoria en vigencia en Chile en los años que nos interesan era herencia de la dictadura militar, lo cual tensionó la aplicación de normas pro migratorias pues, por un lado se aplicaba medidas administrativas basadas en la legislación de 1975 (D. L. N ${ }^{a}$ 1.094, 14 de julio) con variantes en el aparato regional de Antofagasta que atenuaron la rigidez en cuanto a materias educacionales, por ejemplo, asignando un Rut a los niños/as inmigrantes, sin considerar el status de sus progenitores en cuanto a estar regularizados su estada en Antofagasta o su acceso a los servicios de salud, como ha sido constatado en numerosas entrevistas a beneficiados inmigrantes y con autoridades del gobierno de la Presidenta Bachelet (2014-2018). A su vez, diversas organizaciones civiles y no gubernamentales han expuestos la falencia de la normativa migratoria nacional, ahora en proceso de reforma gubernamental, una propiciada durante el primer gobierno del Presidente Piñera (2010-2014) y otra por la segunda administración de Bachelet (Centro Democracia Comunidad, 2013).

Como se ha visto en el área de la salud, por ejemplo, la acción estatal en procura de asistir al inmigrante ha debido fijar estrategias en concordancias con los tratados internacionales para afrontar uno de los temas más difíciles como sociedad entera, la expresividad del racismo, la xenofobia y la asociación entre inmigrante y delincuencia, como ha sido detectado en determinadas encuestas regionales.

En esta perspectiva, el municipio de Antofagasta se sumó a los esfuerzos de la OIM de constituir a la ciudad como espacio de inclusión social, haciendo campañas contra la no discriminación y sensibilizando a los directivos de establecimientos educacionales (OIM, 2018; Carrasco, Flores y Balbontín, 2017). Asumir tal política no ha inhibido presenciar hechos aislados de enfrentamientos callejeros o concentraciones en contra de la inmigración en los últimos años.

Uno de los factores sensibles para la adaptación de la población migrante es el sentirse rechazado. La percepción puede variar desde el lenguaje no verbal hasta las expresiones lingüísticas xenófobas. Pero también puede evidenciarse desde la invisibilidad del sujeto en la atención en determinadas reparticiones (postergación, ninguneo, etc.) o asignarle las variables que inciden en la inseguridad ciudadana (delincuencia, drogas, asesinatos de conmoción pública, etc.). Aun cuando las cifras no refieren una incidencia desmedida entre transgresores y víctimas en la población inmigrante, haciéndose esfuerzos por brindar justicia hacia ésta, ocurre lo mismo entre la disonancia de los datos empíricos y la percepción de los delitos asignados a los extranjeros (Ministerio de RR. EE., 2016).

En este acápite podemos indicar algunos elementos que gravitan en términos estrictamente regionales o que han alcanzado un impacto mediático a nacional e incluso internacional. 
Algunos antecedentes al respecto refieren:

La percepción de la sociedad sobre la presencia de inmigrantes como problema -“muchos extranjeros"- a nivel nacional quedó reflejada en la encuesta MORI-IPP del año 2016 en un 4\%, en su registro regional; sin embargo, a nivel comunal el guarismo asciende como problema a un $13 \%$, constituyéndose en el tercer problema conjuntamente con el desempleo por su porcentaje. Pero, lo preocupante se manifestó en la pregunta específica sobre el impacto de los inmigrantes en la región, donde los porcentajes fueron inequívocos: un $78 \%$ se pronunció por ser malo y muy malo; bueno y muy bueno un $17 \%$ y un $5 \%$ no sabe. En lo que respecta a determinar las frases que reflejaran la actitud sobre los inmigrantes, las respuestas también mostraban una actitud negativa del nativo respecto del extranjero, como se constata en la Tabla 4.

Tabla 4. Propensión de asociar frases al rechazo del inmigrante en Antofagasta

\begin{tabular}{|l|c|}
\hline Vienen a competir por nuestros puestos de trabajo & $69 \%$ \\
\hline Debería haber una ley que les impida entrar & $67 \%$ \\
\hline $\begin{array}{l}\text { Los países más ricos tienen la responsabilidad de aceptar } \\
\text { inmigrantes provenientes de los países más pobres }\end{array}$ & $55 \%$ \\
\hline
\end{tabular}

Fuente. UCN-Mori, 2016.

Concordante con los datos precedentes, la población encuestada asignaba al gobierno central la responsabilidad de encarar y solucionar los problemas que afectaban al espacio regional, siendo los extranjeros con un 7\% de importancia -en cuarto lugar compartido con la cesantía- mientras al Intendente-autoridad regional- se le asignaba la responsabilidad que resolviera el problema de los inmigrantes con un 14\%, siendo el tercero en importancia; igual lugar ocupaba para ser encarado por el alcalde de la ciudad, constituyendo en los casos de los gobiernos regional y local una diferencia mínima en términos porcentuales con los principales tópicos.

Esta postura contraria a los extranjeros queda validada en la pregunta abierta sobre cuáles son los problemas fundamentales de la región, los extranjeros son mencionados en tercer lugar con un $16 \%$.

Entre los años 2016-2017 la encuesta de amarras pudo ampliar el espectro de preguntas y profundizar en las actitudes de la población antofagastina respecto de la migración.

En la comparación a nivel nacional, la inmigración descendía de un 4\% en el año 2016 a un $3 \%$ al año siguiente, lo mismo se apreció a nivel comunal: de un $13 \%$ a un $11 \%$. En el cuadro general, los cambios denotaron una muy significativa estadística en la percepción respecto a la inmigración: si en el año 2016 había un 78\% que estimaba malo y muy malo la llegada de extranjeros, en el año 2017 bajó a un 57\%. En contraste la mirada positiva se acrecentó, de bueno a muy bueno de un $17 \%$ en el 2016 a un $38 \%$ en el 2017 . Lo mismo se correlacionó a nivel de género: la mirada negativa femenina transitó de un $81 \%$ en el 2016 a un $55 \%$ en el 2017 ; mientras la masculina de un $75 \%$ a un $58 \%$ en el bienio examinado.

No obstante, quedaba rondando la disonancia que mostraba la encuesta en cuanto la percepción considerada desde el nivel de educación, donde solo en el estrato de nivel 
superior se constató un $46 \%$ de negatividad a un $49 \%$ en positivo; en contraste, en el nivel de personas con enseñanza media un $63 \%$ consideraba mala a la inmigración y un $31 \%$ buena. A nivel de enseñanza básica un $77 \%$ lo estimaba mala y un $23 \%$ buena.

Un acercamiento al universo etario de los encuestados, las cifras delataban que los mayores de 61 años estimaban mala con un 76\% y buena un 19\%; entre los 41-60 años, un $57 \%$ mala y un 385 buena; entre los 26-40 años, mala un $40 \%$ y buena un $46 \%$ y entre los 18-25 años el porcentaje de $48 \%$ mostraba un empate de la percepción.

Un $45 \%$ consideró que la emigración era un derecho y un $47 \%$ un privilegio.

Un relevante set de preguntas puso en evidencia una mirada más amplia sobre la inmigración latinoamericana, principalmente sobre colombianos, bolivianos y peruanos respecto de los chilenos, como se aprecia en la Tabla 5:

Tabla 5. Cualidades asignadas a los inmigrantes por los antofagastinos

\begin{tabular}{|l|c|c|c|c|c|c|}
\hline $\begin{array}{l}\text { Temas } \\
\text { Nacional }\end{array}$ & $\begin{array}{c}\text { Igualdad } \\
\text { ante la ley }\end{array}$ & Honestos & Trabajador & $\begin{array}{c}\text { Buena } \\
\text { Persona }\end{array}$ & $\begin{array}{c}\text { Cumplen } \\
\text { Con la ley }\end{array}$ & $\begin{array}{c}\text { A quien } \\
\text { Le cree }\end{array}$ \\
\hline Boliviano & $25 \%$ & $12 \%$ & $23 \%$ & $7 \%$ & $9 \%$ & $7 \%$ \\
\hline Peruano & $26 \%$ & $6 \%$ & $24 \%$ & $6 \%$ & $14 \%$ & $8 \%$ \\
\hline Colombiano & $36 \%$ & $3 \%$ & $21 \%$ & $7 \%$ & $8 \%$ & $7 \%$ \\
\hline
\end{tabular}

Fuente. Ucn-Mori, 2018.

De este modo, puede indicarse que la percepción local hacia la inmigración latinoamericana ha ido perfilándose de modo más positivo, conjuntamente con la aplicación de normativas nacionales que penalizan las actitudes de cualquier tipo hacia otra persona con rasgos diversos, desde lo étnico, sexual hasta la custodia de su acervo cultural. Aspectos que la ciudad ha podido implementar con una labor conjunta entre las agencias estatales y edilicias y las universidades y las organizaciones no gubernamentales que trabajan entre la población inmigrante.

Esto lo podremos visualizar más detenidamente en el plano educacional.

\section{LOS CAMPAMENTOS: LA BISAGRA SOCIO-CULTURAL ENTRE LA MARGINALIDAD Y OTEAR LA INSERCIÓN URBANA}

Como hemos aseverado en líneas superiores, la inmigración histórica en Antofagasta, según fuese su cualificación laboral-profesional, pudo insertarse en los distintos barrios que conformaron a la ciudad durante la hegemonía salitrera.

En la actualidad, nos encontramos con una realidad distinta no solamente por los cambios que ha tenido la urbe sino por los cambios operados por la acción del Estado bajo las orientaciones del neoliberalismo económico. Aquello ha significado, relevar en gran medida la acción diferencial estatal en cuando al uso del suelo, su valor y la calidad de la vivienda a construir. Ya quedó en el pasado la edificación de conjuntos habitacionales 
originados por el Estado -las denominadas poblaciones obreras o populares, surgidas de tomas de terrenos o de la planificación fiscal sobre los terrenos públicos a entregar gratuitamente- o por cooperativas (repárese en la importante área residencial de la Coviefi, Cooperativa de Viviendas de los Empleados Fiscales) o el levantamiento de edificios por las denominadas Cajas de Empleados Particulares, del Salitre, etc. O la planificación de la urbe, como fue el sector residencial mesocrático de la Gran Vía (Vallejos Bernal, 2012).

La pobreza tenía posibilidades de esperanza de acceder a un sitio fiscal, vivienda social, conjuntamente con la cercanía de un establecimiento educacional. En la actualidad, como ha subrayado Francisco Sabatini (2015, p. 25), nos hallamos en la entronización del "efecto guetto", como un hecho inédito en Latinoamérica, que marca la "ruptura con el patrón tradicional de segregación". A la dispersión espacial de los grupos medio y altos, se agrega la incidencia de la promoción inmobiliaria y del mercado de los suelos. A la inseguridad ciudadana -delitos, drogas, alcoholismo, redes criminales- se agrega la incertidumbre económica y laboral.

Nos encontramos con el surgimiento de una realidad urbana precaria, donde se anida la línea debajo de la pobreza y de la desigualdad social, rodeada de múltiples metáforas y aforismos para referirse a sus inquilinos por parte de la población popular establecida en poblaciones obreras o en barrios consolidados. El estado no interviene en este encuadre social salvo mediante subsidios, pero no para procurar una solución integral al problema de vivienda, salvo para cautelar a los habitantes de los campamentos de los riesgos naturales o de las instalaciones eléctricas (Portes, Roberts y Grimson, 2005).

El hecho de la realidad de los campamentos y su aumento exponencial entre los años 2010-2016 en 30 asentamientos, refiere que se ha constituido en un problema estructural para el desafío del espacio urbano, la ciudadanía y por cierto la observancia de los derechos humanos, como signo distintivo de la nueva sensibilidad para todos los actores sociales (Fuentes, 2018).

La marginalidad espacial ha acrecentado la vulnerabilidad social -ya consustancial por la población inmigrante- donde el hacinamiento es mayor que la media nacional, carente de servicios básicos, que ha aumentado el riesgo sanitario e incluso vital de esta población latinoamericana (Instituto, 2017; Obach et al., 2017)). En estas circunstancias, el inmigrante ha debido soportar actitudes de discriminación ante el requerimiento de estos servicios, en un porcentaje cercano al 30\% (Equipo, 2017).

La ciudad en su generalidad se mueve bajo los patrones que Tônnies había caracterizado como los rasgos dela sociedad (Gesellschaft), en sus características de los instrumentos jurídicos, la actividad bancaria, el anonimato, la distancia social entre sus miembros; en contraste, los trabajos de campo llevados a cabo en el conjunto de campamentos que conforman el gran campamento de Los Arenales, en el sector noreste de la ciudad, habitado por distintos grupos de inmigrantes latinoamericanos, han perfilado rasgos que pueden asimilarse a lo que Tônnies había descrito como comunidad (Gemeinschaft) donde la propia precariedad de la vida, el apoyo mutuo entre sus integrantes, la identidad social entre sus miembros, el compartir los mismos lugares "públicos" que constituyen la àgora para sus debates organizativos y decisiones colectivas, refuerzan el conocimiento mutuo, el valor de la confianza y la palabra empeñada, como elementos centrales del compromiso (Tönnies, 1946, 1947). Para Sennett, este conjunto del espacio urbano, entre los habitantes citadinos, dominados por las acciones contractuales, y los que habitan los campamentos, enfatizaría su perspectiva de que la ciudad es un encuentro de extraños (Sennet, 2022). La capacidad 
de poder asumir las habilidades del mismo escenario, aun en el anonimato, la alteridad, la impersonalidad conjugando el péndulo entre la simpatía, como forma de solidaridad en el sufrimiento, en la perspectiva de identificarse con el otro, y de empatía, como modalidad de aproximarse a comprender como viven los otros (Muñoz, 2014).

El sociólogo chileno Pedro Morandé, ha caracterizado a la ciudad chilena contemporánea como claramente multicéntrica dominada por el consumo, puesto que ni la tradición residencial, el poder político ni el empleo,

tienen la capacidad de centripetar la dinámica social", pero tampoco logra solucionar la situación de los excluidos, los transeúntes recolectores, los que se insertan en el trabajo informal...Esta tendencia retroalimenta la estigmatización de los grupos socialmente más vulnerables y de sus lugares de residencia, promoviendo la discriminación (Morandé, 2004, pp. 45-46).

Este contexto muestra lo contradictorio del capitalismo tardío o el predominio del neoliberalismo en las resoluciones socio-económicas. Los bienes de capitales, las mercaderías, las ideas y los materiales culturales junto a las transferencias tecnológicas circulan libremente, conjuntamente con las personas en el subcontinente sudamericano. La valorización de tal libertad se opaca cuando se observa que la libertad humana debería ir acompañada con una dignificación de su habitar, que se ve desmedrado en la propia condición ante el Estado, la precariedad en el mercado laboral que se proyecta en la inseguridad social hacia su entorno más cercano, la desconexión entre el crecimiento económico y la condición de marginalidad del inmigrante, la estigmatización territorial de su lugar de residencia, llamado por Pétonnet "espacios penalizados", que el estudioso francés Loic Wacquant (2013) ha denominado la disolución del lugar, "pérdida de un marco humanizado, culturalmente familiar y socialmente tamizado, reflejo de una condición de "precariado" (283). Los campamentos de Antofagasta exhiben la realidad descrita. Nos interesa abordarlos desde la experiencia practicada en los siete campamentos conformando el Macro-campamento Los Arenales.

El poblamiento del espacio cercano al Liceo Los Arenales, como el Campamento Eulogio Gordo, fue lento, a partir del año 2012. El campamento Rayito de Sol se gestó por la misma época, con siete familias. Una dirigente de campamentos nos relata: "Desde el 2014 se constituyeron como campamentos y comités. Con algunas políticas de gobierno sacan gente y llegan otros y así, ahora como campamento nos están ordenando, con direcciones, números" (Entrevistas, 2018).

La habilitación de la serie de campamentos fue una concatenación de ir aprovechando los avances de otras, en el abastecimiento de luz eléctrica, agua. La dirigente Susy Chacayo nos refiere

El (Campamento) Rayito de Sol se alimenta de los postes de luz de la calle Julio Montt Salamanca, por grupos van a distintos postes, entonces no hay mayor problema. Con el agua potable, nosotros nos hemos organizado para conectar la manguera al grifo y eso se conectaba a unos tubos colocados por nosotros y da a todas las casas y así llenábamos los tambores de agua y cuando ya se estaba acabando el agua, de madrugada los volvíamos a llenar, estuvimos un buen tiempo así hasta que nos dijeron 
que nos podíamos conectar con una red de agua que viene de la parte de arriba, entonces ahí nos fuimos conectando, donde ahora está (el Campamento) Nuevo Amanecer Latino (Entrevistas, 2018).

El proceso de transformación de los campamentos ha supuesto la intervención gubernamental, puesto que en ellos concurren tres variables de relevancia socio-política: el tema de la pobreza (Fundación, 2017), la superación de los campamentos y la regulación de la inmigración.

El estudio de la Fundación para la Superación de la Pobreza pone de manifiesto la debilidad institucional en materias culturales y sociales tendientes a fortalecer la convivencia. Una de las conclusiones que explica la aparición de los campamentos y su asociación a los inmigrantes y la constitución de un problema urbano grave, se revela en la afirmación:

Somos un país donde el clasismo y el racismo siempre han estado presentes. Para muchos chilenos y chilenas, la experiencia de vivir en forma segregada, donde no es posible acceder a un trabajo digno, asistir a una escuela de calidad o ser escuchados donde se toman decisiones, es una realidad cotidiana e inmodificable (Fundación, 2017, p. 74).

Una de las medidas estatales fue el acuerdo conjunto de 30 de mayo de 2015 entre la dirigencia de las Agrupaciones de Campamentos Américas Unidas y Campamentos La Unión Hace La Fuerza y el Gobierno Regional, para afrontar un Plan de Superación de los Campamentos, principalmente cuando una serie de factores había incidido en la multiplicación de los campamentos en Antofagasta. Uno de estos fue la no existencia de una política de viviendas sociales durante el primer gobierno de Sebastián Piñera (Obach $e t$ al., 2017, p. 337). Solo se levantaron 88 viviendas sociales. Esto coadyuvó a que el déficit de soluciones habitacionales se acrecentara. Otro factor fue la localización de las viviendas de campamentos en áreas topográficas de alto riesgo, sea por el peligro de los aluviones o bien por el paso del tendido de cables de alta tensión (Intendencia, 2018). La realidad de la vivienda social y los campamentos- un tópico de discrepancia entre las autoridades y la dirigencia vecinal, pues algunos campamentos se totalizan en un gran campamento, variando su cantidad- haciendo Serviu entrega de terrenos fiscales gratuitos y planteando áreas de viviendas sociales en el año 2017 (Entrevista a de la Vega, 2018; Entrevista a Contreras, 2018).

Esto se tradujo en un plan de entrega de viviendas sociales por parte del Servicio de Viviendas y Urbanismo, durante la segunda administración de Bachelet (2015-2018) y el traslado de las familias de 535 viviendas del Macro Campamento Balmaceda hacia los denominados Barrios Transitorios. Proceso que concitó críticas de parte de organizaciones no gubernamentales. Las voces discrepantes apelaban al derecho de elegir donde vivir o postular a una vivienda definitiva. Constituyó el Plan una estrategia viable que tardó en ultimarse y se verificó hacia la segunda mitad del año 2017 (Entrevista Barrientos, 2018).

La vinculación o asociación entre los campamentos y la inmigración como un eje de la percepción de la sociedad local, quedó registrada en la encuesta llevada a cabo entre el Instituto de Políticas Públicas-UCN y MORI del año 2018. Los resultados refieren como una temática de gran significación con un porcentaje altísimo: un $81 \%$ estimó que 
le importaba la presencia de los campamentos en la ciudad en contraste con el $11 \%$ que lo desestimó. Es posible asociar la existencia de los campamentos con la inmigración, dado el nexo que se establecía en los medios de comunicaciones citadinos de modo persistente. Importante en esta percepción era la resolución del problema, que en orden decreciente arrojaba que debía ser solucionado por: alcalde, 29\%; gobierno central, 27\%; gobierno regional, $9 \%$, intendente, $9 \%$; municipio, $8 \%$; las autoridades, $4 \%$ y los políticos, $3 \%$.

En cuanto a la jerarquía de problemas a solucionar por el intendente, figuraban la inmigración con un 2,7\% y los campamentos con el 2,6\% siendo los dos últimos de un total de nueve; y a nivel del alcalde, los campamentos estaban en cuarto lugar con un $2,7 \%$ y en el último lugar -de doce- la inmigración con un 2,7\%.

\section{EL MIGRANTE EN EDAD ESCOLAR: DE LAS TRIBULACIONES A LA ESPERANZA DE LA POLÍTICA INTERCULTURAL}

El inmigrante latinoamericano en el periodo estudiado ha exhibido una formación educacional superior a la media del nacional. Y esto ha quedado establecido en la estadística oficial donde, debe recordarse que la mayoría de los extranjeros, son latinoamericanos. En la Tabla 6 se puede visualizar la preparación educacional.

Tabla 6. Inmigrantes en Antofagasta: Formación educacional en el lapso 2005-2017

\begin{tabular}{|l|c|c|c|c|c|c|c|}
\hline Años & Básico & Medio & Ninguno & No informa & Pre-básico & Técnico & Universitario \\
\hline $\mathbf{2 0 0 5}$ & 30 & 96 & 5 & 3038 & 0 & 47 & 32 \\
\hline $\mathbf{2 0 0 6}$ & 26 & 79 & 5 & 1807 & 0 & 32 & 24 \\
\hline $\mathbf{2 0 0 7}$ & 101 & 368 & 30 & 1549 & 6 & 145 & 83 \\
\hline $\mathbf{2 0 0 8}$ & 362 & 1335 & 60 & 18 & 31 & 417 & 306 \\
\hline $\mathbf{2 0 0 9}$ & 546 & 1950 & 85 & 19 & 48 & 581 & 379 \\
\hline $\mathbf{2 0 1 0}$ & 910 & 2858 & 143 & 21 & 89 & 801 & 514 \\
\hline $\mathbf{2 0 1 1}$ & 971 & 3881 & 141 & 179 & 79 & 893 & 518 \\
\hline $\mathbf{2 0 1 2}$ & 1324 & 5231 & 213 & 104 & 102 & 1038 & 689 \\
\hline $\mathbf{2 0 1 3}$ & 1414 & 4988 & 216 & 119 & 87 & 853 & 579 \\
\hline $\mathbf{2 0 1 4}$ & 3336 & 8601 & 315 & 874 & 205 & 1190 & 777 \\
\hline $\mathbf{2 0 1 5}$ & 1910 & 4198 & 112 & 6502 & 152 & 636 & 427 \\
\hline $\mathbf{2 0 1 6}$ & 545 & 1751 & 77 & 10007 & 36 & 284 & 279 \\
\hline $\mathbf{2 0 1 7}$ & 621 & 2319 & 112 & 9129 & 52 & 286 & 281 \\
\hline
\end{tabular}

Fuente. Departamento de Extranjería, 2018. 
Cabe puntualizar a nivel general que el gobierno de Chile, desde el año 2005, impartió instrucciones para los derechos de los estudiantes inmigrantes en los establecimientos educacionales. Diez años más tarde, el Instructivo Presidencial 5 estableció los Lineamientos e Instrucciones para la Política Nacional Migratoria, acomodando éstos a los estándares de los derechos humanos, planteándose procedimientos de identificador provisorio escolar, convalidación de estudios y medidas para la inclusión escolar (Normativa, 2016).

Empero en el gobierno regional, se plantearon medidas que apuntaron a agilizar la inserción del estudiante inmigrante:

Nosotros nos adelantamos un poco a la "Escuela somos todos" y nos adelantamos un poco al "Chile te recibe", donde hoy todos los niños que van a la educación se regularizan rápidamente y además con una visa que es gratuita. En ese tiempo nosotros estábamos fomentando una visa de estudiante que tiene un pequeño problema para los adolescentes, les prohíbe trabajar, porque la visa de estudiante solamente puede ser respecto de la condición de dependiente y también para los universitarios que pueden optar a las prácticas profesionales remuneradas, entonces a veces había que hacer excepciones para que puedan retribuir, y nos adelantamos porque nos parecía muy complejo que autoridades comunales vieran la educación de niños migrantes como un gasto, por lo tanto nosotros nos reunimos muchas veces con la Cdms y con las municipalidades de la provincia para explicarles la confusión, primero de lo discursivo y luego desde los instrumentos que existen (Entrevista a Riveros, 2018).

Aquello apuntaba a regularizar en el año 2017 los más de 24.000 estudiantes irregulares (UDP, 2017). El estudio de la Universidad Diego Portales que citamos indicaba que determinadas barreras impedían el ejercicio pleno de los derechos de los alumnos inmigrantes (desde falta de documentación para acceder a beneficios del sistema, falta de comprensión de la interculturalidad hasta ausencia de herramientas metodológicas (UDP, 2017, p. 334).

La preocupación del gobierno edilicio por la situación en el ámbito educacional de su competencia tuvo una inflexión en el año 2015, cuando dio inicio al Programa La Escuela Somos Todos en Antofagasta, tendiente a regularizar la situación de miles de niños, mediante el apoyo de la obtención de visa, obtener el Rut, certificar estudios y apoyo en alimentación, salud y becas Mediante un ejercicio de intuición, escuchando y conociendo las situaciones, se aplicó el programa en doce establecimientos. Un ícono en esto ha sido el liceo Mario Bahamonde Silva (Grupo Educativo, 2017). La condición de la migración en Antofagasta ha exigido que el municipio se haya incorporado a la implementación de la educación intercultural, mediante una oficina específica. Una situación que se sumaba las cinco regiones que tenían oficina y programa para los migrantes. El municipio estableció en el 2016 el programa "Casa de la Diversidad" (Asociación, 2016). En esta orientación buscó el apoyo de otras entidades civiles para emprender otras iniciativas. Con el apoyo del Servicio Jesuita de Migraciones, abril de 2018, postuló al Sello Migrante que constituye la certificación de una ciudad libre de discriminación, según acuerdo en mayo de 2018, otorgado por la Dirección General de Extranjería y Migración (Asociación, 2017).

Es posible conjeturar que en el universo de los inmigrantes latinoamericanos en Antofagasta se constate la situación que un gran porcentaje, cercano al $60 \%$ concurra hacia establecimientos municipales y un $36 \%$ hacia los colegios particulares subvencionados, opción que comenzó a desaparecer con la promulgación en el año 2016 de la Ley de Inclusión 
Escolar (Joiko-Vásquez, 2016, p. 136). Los datos apuntan a un crecimiento explosivo de la matrícula escolar en Antofagasta, de 677 alumnos en el año 2010 se pasó a 4.120 en el año 2016 (Santana, 2017). Si bien existe una cierta hegemonía en cuanto al número de establecimientos municipales -y su alumnado- en los últimos años ha habido preocupación por los porcentajes de matriculados, que es bajo comparado con otras comunas e incluso con el promedio nacional, principalmente en las cohortes etarias de menores de 5 años (22\%) y entre los 15 y 19 años (72\%), mientras un $9 \%$ de la población no tiene ningún tipo de educación y el porcentaje es de un 15\% los que acceden a la educación superior. Un 5\% de la población exhibe educación universitaria completa (Municipalidad, 2013).

No obstante, las oportunidades de acceso a la educación han sido aprovechadas por los niños y jóvenes inmigrantes.

La experiencia del trabajo de campo del Voluntariado Social y la Escuela de Educación de la Universidad Católica del Norte, ha posibilitado orientar aptitudes de niños para su ingreso al sistema escolar y seguidamente han formado a jóvenes de la educación básica y media en las competencias y habilidades exigidas en el sistema, logrando resultados que permitieron que los dos primeros jóvenes del Macro-Campamento Los Arenales pudieran ingresar a la universidad.

Esta realidad se ha visto reflejada en la matrícula de jóvenes inmigrantes en diversos establecimientos universitarios regionales, como ser en el caso de la Universidad Católica del Norte. En el año 2018 la mencionada universidad contaba entre sus alumnos con 25 colombianos, 49 peruanos, 38 bolivianos, 7 ecuatorianos, 4 venezolanos, 4 argentinos (Comunicación Castillo, 2018).

Interesante-aun cuando las cifras son contradictorias- es visualizar la segunda generación de migrantes. En un trabajo pionero (Pavez-Soto, 2017), ha podido, en base de información del Servicio del Registro Civil e Identificaciones, determinar para el periodo 1990-2016 que los hijos e hijas de madres y padres extranjero, revela que después de la Región Metropolitana, es Antofagasta la que arroja los indicadores más altos: 8,3\% de Madre extranjera, y un 4,4\% de Madre nacionalizada, de un 6,5\% de Padre extranjero, en contraste a un 3,6\% de padre nacionalizado. Se debe apostillar que los nacionales de Perú, Bolivia, Ecuador y Colombia expresan los mayores porcentajes de madres y padres nacionalizados, siendo los dos últimos países los progenitores nacionalizados superan a los que han mantenido su nacionalidad.

En tal sentido, el proyecto IMI-UCN estableció desde el año 2016 una acción de intervención educacional de carácter intercultural en los liceos que tuviesen mayor población de alumnos inmigrantes, a través de estrategias dinámicas psico-pedagógicas que, a su vez, complementaban las actividades con niños(as) de los campamentos de Los Arenales, contando con una red de voluntarios que coadyuvaron a la Escuela de Educación con sus prácticas educacionales tendientes al reforzamiento de unidades didácticas, tareas en pro de su inclusión en establecimientos de educación básica y preparación para el ingreso a la Universidad (Informe, 2017). Esto con otras acciones impulsadas por el Gobierno Regional transformaba a la ciudad en una experiencia de docentes con alumnos migrantes, en términos cuantitativos después de Santiago. Si la Región Metropolitana registraba un $35,9 \%$, Antofagasta exhibía un $10,3 \%$, pero si con una similitud que sus alumnos extranjeros podían rendir mejor por contar con un curriculum distinto al nacional, como lo planteaban los docentes con tales experiencias, anotando que un 67,3\% era determinante como factor principal en su rendimiento (Resultados, 2018). 
Una materia sensible para la población inmigrante ha sido la educación pre-escolar para sus hijos (as), la que ha demandado para la Junta Nacional de Jardines Infantiles, JUNJI, la contratación de personal en el área educacional afín con políticas de integración e interculturalidad, toda vez, como ha sido reconocido por entidades gubernamentales:

Los niños y niñas en situación de inmigración no sólo deben mediar con un medio nuevo, distinto a sus orígenes culturales, sociales, sino que además experimentan la lejanía y pérdida de vínculo con sus redes familiares (abuela, abuelo, tíos, primas, etc.), sumándose a que muchas veces sus madres o padres deben trabajar largas y extensas jornadas. Por ello resulta tan importante para los niños y niñas que se encuentran en esta situación el acceso y permanencia a un programa de Educación Parvularia que facilite su inclusión sin perder de vista su identidad, es decir programas pertinentes y adecuados a sus necesidades de aprendizaje, desarrollo y bienestar (Junji, 2013, p. 16).

En los diversos jardines infantiles la población inmigrante tanto masculina como femenina en Antofagasta bordeaba el $4 \%$ respectivamente.

Es relevante que en los permisos de residencia definitiva otorgados entre los años 2011-2015, los inmigrantes en cuanto a su nivel educacional se distribuyeron en: $6,7 \%$ en universitarios, $8,5 \%$ técnicos, 49,5\% educación media, 17,9\% educación básica, 2,2\% prebásico, 2,5\% ninguno, 3,2\% no indica, 9,4\% no informa (Seremi Salud, 2017).

\section{CONCLUSIONES}

La ciudad de Antofagasta ha sido uno de los epicentros del proceso migratorio latinoamericano que se ha hecho sentir, a partir del 2011 adelante, aunque la presencia había comenzado a detectarse hacia el 2005.

Aproximarse a la realidad del inmigrante en Antofagasta significa que la política estatal bocetada a comienzos del año 2000 de desterrar los campamentos en nuestro país, no solo era una dimensión habitacional casi marginal en Antofagasta, sino, al contrario, se multiplicó llegando a constituirse en sinonimia con el asentamiento inmigratorio latinoamericano.

Los desafíos han sido múltiples. Por una parte, recepcionar a contingentes demográficos no tradicionales- de los países limítrofes- como colombianos, ecuatorianos y venezolanos, se ha traducido en un "choque cultural" por el acervo socio-cultural (música, costumbres, gastronomía, giros idiomáticos, etc.) que ha planteado el desafío a la sociedad regional de reafirmar los pilares de la democracia, el pluralismo, la tolerancia y el respeto a la diversidad, enfrentando recelos, recriminaciones y expresiones racistas, xenófobas. En tal sentido, ha debido la sociedad entera y el estado y el municipio, perfilar acciones, políticas, normativas que han exigido superar las consideraciones de la ley migratoria de 1975-en pro de observar el derecho internacional y su protección total al migrante como sujeto de derechos- y llevar a cabo paliativos para "enmendar" las orientaciones de la política neoliberal, no proclive en asignar cobertura social en los ámbitos en que se debe aplicar políticas de inclusión del inmigrante en el espacio urbano, en las áreas de la atención sanitaria, en la participación en los establecimientos educacional en pro de una dimensión de interculturalidad. 
Tales acciones, como las hemos expuesto, deben encuadrarse en una visión holística del inmigrante de cara ante las agencias estatales, la edilicia y la sociedad regional. En esta visión más global, hallamos la condición del inmigrante en su situación de marginalidad, desde sus trabas para regularizar su permanencia en todo lo que proyecta como ciudadano, hasta su vida cotidiana vivienda en la precariedad, bajo el recelo o rechazo de importantes segmentos sociales, y la dificultad para acceder a los servicios básicos (salud, educación, vivienda, etc.).

Lo observado en Antofagasta constituye el pulso de un rasgo distintivo en Chile. Ha sido la ciudad más latinoamericana, desde sus orígenes, y este nuevo flujo masivo inmigratorio devuelve esta dimensión de cosmopolita, plural que la acompañó en la era salitrera. Ahora, con más exigencias para el inmigrante y el nacional.

\section{REFERENCIAS BIBLIOGRÁFICAS}

Asociación de Municipalidades de Chile (2016). Impacto de la migración a nivel local: ¿Qué han hecho los municipios al respecto? Santiago de Chile: Dirección de Estudios AMUCH Asociación de Municipalidades de Chile.

Asociación de Municipalidades de Chile (2017). Inmigrantes con permanencia definitiva en las comunas de Chile ¿Qué nos dicen los datos 2006-2016? Santiago de Chile: Dirección de Estudios AMUCH Asociación de Municipalidades de Chile.

Bernales, M., Cabieses, B., McIntire, A. M. y Chepo, M. (2017). Desafíos en la atención sanitaria de migrantes internacionales en Chile. Revista Peruana de medicina experimental y salud pública, 34(2), 167-175.

Carrasco, D., Flores, K. y Balbontín, S. (2017). Quiero aprender de ti. Informe de buenas prácticas de inclusión migratoria en sectores vulnerables. Regiones de Antofagasta, BíoBío-y Metropolitana. Santiago de Chile: Universidad Bernardo O'Higgins-Ministerio de Desarrollo Social-Observatorio Internacional de Migraciones.

Centro Democracia Comunidad, Ciudadano Global, Organización Internacional del Trabajo, Oficina Especializada de Derechos Humanos de la Corporación de Asistencia Judicial, Instituto Católico Chileno de Migración, Libertades Públicas A. G. (2013). Un Chile Abierto: Propuestas para una Nueva Ley de Migración. Santiago: Centro Democracia y Comunidad-Konrad Adenauer Stiftung. $\mathrm{N}^{\circ}$ 2. Disponible en https://www.cdc.cl/web/un-chile-abierto-propuesta-para-unanueva-ley-de-migracion. Consulta 8 de junio de 2018.

Comunicación Castillo S., E. (2018). Funcionaria Dirección General Estudiantil, Universidad Católica del Norte.

De las Heras, M. J. (2016). Los migrantes como sujetos del sistema de protección social en Chile. Temas de Agenda Pública, Año 11, (91), 1-11.

Departamento de Extranjería y Migración. Gobernación Provincial de Antofagasta (2018). Resumen estadístico de atenciones. Periodo 2005-2017. Información remitida por el Departamento de Extranjería y Migración. Gobernación Provincial de Antofagasta (2018). Resumen estadístico de atenciones. Primer y tercer trimestre 2018.

Equipo Asesor Sectorial de Salud de Migrantes (2017). Política de Salud de Migrantes Internacionales en Chile. Borrador. Santiago de Chile: Ministerio de Salud-Fonasa- Superintendencia de Salud.

Fernández Briones, Mg. SP, M. (Ed.). (2017). Diagnóstico de Salud de la Población Inmigrante Región de Antofagasta, 1 de agosto. Antofagasta: Seremi de Salud.

Fuentes, J. M. (2018). Nuevas territorialidades, el proceso de campamentación en la ciudad de Antofagasta. Revista de Investigación Social. Un Techo para Chile, 15(24), 97-112.

Fundación Casa de la Paz -Embajada de Canadá- Servicio Jesuita a Migrantes (2018). Derechos 
Humanos y Empresas. Desafíos para la inclusión de migrantes en Antofagasta. Un diagnóstico de percepción. Santiago de Chile: Casa de la Paz.

Fundación Superación de la Pobreza (2017). Fronteras invisibles. Convivencia urbana y migración en Antofagasta. Santiago de Chile: Ministerio del Interior y Seguridad Pública- Fundación Superación de la Pobreza-Servicio País.

González, J. A. (2011). Notas sobre la inmigración argentina en la precordillera argentina durante el ciclo salitrero. Estudios Atacameños, (42), 189-204.

(2014). La inmigración europea en Antofagasta y su influencia comercial durante el ciclo salitrero 1880-1910. Algunas notas. En M. Tapia Ladino y A. González Gil (Comp), Regiones fronterizas. Migración y los desafíos para los Estados nacionales latinoamericanos (pp. 335359). Santiago de Chile: RIL editores.

. (2016). Una ciudad del desierto y la migración. La experiencia de Antofagasta. En E. T. ello Bianchi (Editora), Sociedad, Valores y Economía: Aproximaciones a la complejidad de nuestro tiempo (pp. 206-256). Antofagasta. Ediciones Universitarias Universidad Católica del Norte.

. (2017). La educación en Antofagasta durante el liberalismo económico y el auge del salitre: 1880-1920. En B. Silva Torrealba (Comp.) Historia Social de la Educación chilena. Tomo 3. Instalación, auge y crisis de la reforma alemana. Chile 1880 a 1920. Estudios finales. (pp. 88121). Santiago de Chile: Ediciones Universidad Tecnológica Metropolitana.

González, J. A., Lufin, M. y Galeno, C. (2014). Apuntes sobre los argentinos en la ciudad de Antofagasta: 1880-1930. Patrones de emigración y de localización espacial. En B. Estrada (Comp.). Inmigración Internacional en Chile. Un tema en desarrollo (pp. 55-81). Viña del Mar: Diegho Impresores.

. (2017). Mujeres latinoamericanas en el mercado laboral de Antofagasta durante el ciclo salitrero, 1880-1930. Estudios Atacameños, (54), 153-178.

. (2018). La migración de las colonias minoritarias europeas y latinoamericanas en el desierto de Atacama. Españoles, italianos, colombianos y ecuatorianos en Antofagasta, 18801930. En M. Tapia Ladino, N. Liberona Concha (Comp). El afán de cruzar fronteras. Enfoques transdisciplinarios sobre migraciones y movilidad en Sudamérica y Chile (pp. 223-257). Santiago de Chile: RIL editores. Instituto de Estudios Internacionales Universidad Arturo Prat.

Grupo Educativo (2017). Bienvenidos a la diversidad. Levantamiento de experiencias con estudiantes migrantes en establecimientos educacionales de la Corporación de Desarrollo Social de Antofagasta. Antofagasta: Arquetipo-Grupo Educativo.

Informe Proyecto IMI-UCN (2017). Informe de Actividades del Proyecto IMI-UCN. Voluntariado Social. Antofagasta: Dirección General de Pastoral Universitaria y Cultura Cristiana, Universidad Católica del Norte.

Instituto de Ciencias e Innovación en Medicina (2017). Escenario actual de la vida y salud de migrantes en la comuna de Antofagasta. Santiago de Chile: Programa de Estudios Sociales en Salud, Instituto de Ciencias e Innovación en Medicina, Facultad de medicina Clínica Alemana.

Instituto de Políticas Públicas, Universidad Católica del Norte- MORI. (2016). Barómetro de Antofagasta, agosto. Disponible en https://www.politicaspublicasdelnorte.cl/barometroantofagasta/ Consulta 6 de junio de 2018.

Intendencia Región de Antofagasta (2018). Plan Superación de Campamentos 2015-2018. Antofagasta: Gobierno Regional-Región de Antofagasta.

Joiko, S. y Vásquez, A. (2016). Acceso y elección escolar de familias migrantes en Chile: "No tuve problemas porque la escuela es abierta, porque acepta muchas nacionalidades". Calidad de la Educación, (45), 132-175.

JUNJI-Ministerio de Educación (2013). Documento de Consulta. Población Inmigrante. Santiago: Ministerio de Educación.

Martínez Bolaños, C. (s/f). «Una mirada a la inmigración ecuatoriana en Chile». Revista Afese, Asociación de Funcionarios y Empleados del Servicio Exterior Ecuatoriano, 54, 222-238. 
Estudios Pedagógicos XLVI Nº 2: 359-379, 2020

MIGRACIÓN LATINOAMERICANA EN SITUACIÓN DE MARGINALIDAD. CAMPAMENTOS Y EDUCACIÓN EN

ANTOFAGASTA, 2012-2018

Recuperado el 6 de abril de 2016 de www.afese.com/img/Revistas/Revista54/ inmigracionchile. pdf

Ministerio del Interior y Seguridad Pública (2014). Migración en Chile 2005-2014. Santiago de Chile: Departamento de Extranjería.

Ministerio de Relaciones Exteriores-Defensoría Penal Pública-Ministerio Público de ChileMinisterio de Justicia-Carabineros de Chile-Instituto nacional de derechos Humanos-Policía de Investigaciones (2016). Boletín Estadístico $N^{o}$ 2. Mesa Interinstitucional de acceso a la Justicia de Migrantes y extranjeros. Santiago de Chile: Editora e Imprenta Maval Ltda.

Morandé, P. (2004). Comportamientos sociales en la ciudad. En Patricio Tupper (Editor) Hacer Ciudad (pp. 39-48). Santiago de Chile: Centro Chileno de Urbanismo-Agrupación Defendamos la Ciudad.

Municipalidad de Antofagasta (2013). Plan de Desarrollo Comunal de Antofagasta 2013-2022. Volumen I Diagnóstico. Antofagasta: Pulso S.A. Consultores.

Muñoz Miralles, A. (2014). La construcción del carácter frente a las contradicciones del nuevo capitalismo en Richard Sennett. Castellón de la Plana: Universitat Jaume i de Castelló.

Obach, A., Cabieses, B., Chepo, M. y McIntyre, A. (2017). Estudio de caso: comuna de Antofagasta. En Cabieses, B., Bernales, M., McIntyre, A. M., La migración internacional como determinante social de la salud en Chile. Evidencia y propuestas para políticas públicas. Santiago de Chile. Universidad del Desarrollo.

OIM (2018). Programa los migrantes y las ciudades. Sistematización 2014-2017 Publicación 1. Santiago de Chile: OIM. Misión Chile.

Pavez-Soto, I. (2017). DEM investiga "Segundas Generaciones" de migrantes en Chile. Integración, derechos y políticas públicas. Santiago de Chile: Departamento de Extranjería y Migración, Ministerio del Interior y Seguridad Pública.

Portes, A., Roberts, B. y Grimson, A. (Ed) (2005). Ciudades latinoamericanas. Un análisis comparativo en el umbral del nuevo siglo. Buenos Aires: Prometeo libros.

Red Chilena de Migración e Interculturalidad (2011). Informe alternativo Chile. Convención Internacional sobre la Protección de los derechos de todos los trabajadores migratorios y de sus familiares. Santiago: Red Chilena de Migración e Interculturalidad.

Sabatini, F. (2015). La ruptura del patrón de segregación y su significado teórico y práctico. En Agilar, A. G., Escamilla, I. (Coordinadores). Segregación urbana y espacios de exclusión. Ejemplos de México y América Latina (pp. 25-46). México: Unam-Maporrúa.

Santana, F. C. (2017). Antofagasta aumentó un 608\% su matrícula de estudiantes extranjeros en los últimos seis años. Santiago de Chile: El Mercurio, 29 de enero.

Sennett, R. (2002). El declive del hombre público. Barcelona: Editorial Península.

Stefoni, C., Acosta, E., Gaymer, M. y Casas-Cordero, F. (2010). El derecho a la educación de los niños y niñas inmigrantes en Chile", Cuadernos Deusto de Derechos Humanos, (58). Bilbao: Universidad de Deusto.

Subsecretaria de Educación. Ord. $\mathrm{N}^{\circ}$ 2/000894,7 de noviembre de 2016. Disponible en https:// migrantes.mineduc.cl/wp-content/uploads/sites/88/2017/04/7-ORD.894-Mineduc-Migrante.pdf Consulta 6 de marzo de 2018.

Taylor, J. (2014). ¿La unión que nos separa? La estructura de la comunidad colombiana en Antofagasta, Chile. Tesis de maestría en estudios latinoamericanos. Departamento de Estudios Latinoamericanos, Universidad de Leiden. Recuperado el 4 de abril de 2016 de https:// openaccess.leidenuniv.nl/handle71887/28552

Tönnies, F. (1947). Comunidad y sociedad, Buenos Aires: Editorial Losada. . (1946). Principios de Sociología. México: Fondo de Cultura Económica.

UDP-Centro de Derechos Humanos (2017). Informe anual sobre derechos humanos en Chile 2017. Santiago de Chile: Ediciones Universidad Diego Portales. Disponible en http://www. derechoshumanos.udp.cl/derechoshumanos/informe-ddhh-2017/ Consulta 6 de junio de 2018. 
Universidad Alberto Hurtado. (2018). Resultados 4to Censo Docente MIGRACIÓN: Su impacto en la práctica docente. Disponible en http://educacion.uahurtado.cl/wpsite/wp-content/ uploads/2018/07/RESULTADOS-CENSO-DOCENTE-MIGRACION.pdf Consulta 6 de junio de 2018.

Universidad Católica del Norte- IPPUCN, Instituto de Políticas Publicas-MORI, Market Opinión Research International (2018). Barómetro de junio 2017.Santiago: MORI.

Vallejos Bernal, J. (Comp) (2012). La historia de la construcción en Antofagasta... la primera piedra. Antofagasta: Emenor Impresores.

Wacquant, L. (2013). Los condenados de la ciudad. Gueto, periferias y estado. Buenos Aires: Siglo Veintiuno Editores.

\section{ENTREVISTAS}

Entrevistas a dirigentes y pobladoras de los Campamentos de Los Arenales, agosto de 2018.

Entrevista a abogado Ignacio Barrientos, marzo de 2018.

Entrevista a Gobernadora Provincial, Fabiola Riveros, enero de 2018.

Entrevista a Isabel de la Vega, Directora de Serviu, marzo de 2018

Entrevista a Yasna Contreras, Encargada de la Unidad de Campamento de Serviu, marzo de 2018. 
